\title{
17 A PLASTICIDAdE CRIATIVA POSSIBILITAdA PELA SOCIOPOÉTICA: A PERSPECTIVA DA CRIAÇÃO DE RELAXAMENTOS
}

\author{
| Paula Isabella Nunes da Fonseca; Pamela Gioza da Silveira²; Cláudia Mara de Melo Tavares³; José Carlos Carvalho ${ }^{4}$ |
}

\section{RESUMO}

OBJETIVO: Destacar a plasticidade criativa presente no processo de criação das técnicas de relaxamento inerente a etapa de produção de dados na pesquisa sociopoética.

MÉTODO: Análise crítica dos relaxamentos utilizados na produção de trabalhos académicos baseados segundo a pesquisa qualitativa e numa abordagem da perspetiva da Sociopoética. Realizou-se análise com base nos princípios constitutivos da Sociopoética dispostos em literatura de base e em artigos sobre a abordagem dispostos na Biblioteca Virtual em Saúde.

RESULTADOS: Por compreender o homem como ser político, social, com igualdade de direitos e que considera o corpo, a criatividade e a espiritualidade na construção do conhecimento (Gauthier, 2005) para produção e assimilação dos dados, a Sociopoética permitiu a construção de relaxamentos contextualizados com os temas estudados de modo que seu alinhamento junto às técnicas de produção de dados corroboraram para o desvelar mais espontâneo e libertário por parte dos co-pesquisadores nas investigações.

CONCLUSÃO: A liberdade criativa oferecida pela Sociopoética na construção dos relaxamentos não engessa esta etapa, o que possibilita o diálogo entre os objetivos do estudo e os passos da produção de dados, a começar pelo relaxamento. Deste modo, amplia-se e se potencializa a expressão dos co-pesquisadores na pesquisa a ser desenvolvida.

\section{PALAVRAS-CHAVE: Relaxamento; Coleta de dados, Enfermagem Psiquiátrica; Saúde Mental}

\section{RESUMEN}

"Plasticidad creativa posible por la sociopoética: una perspectiva de creación de los relajaciones"

OBJETIVO: Resaltar la plasticidad creativa presente en el proceso de creación de las técnicas de relajación inherente a la etapa de producción de datos en la sociopoética.

MÉTODOLOGIA: Análisis crítico de las relajaciones utilizadas na prodición de trabajos académicos según lo método cualitativo y enfoque metodológico la sociopoética. Se realizó un análisis basado en los principios subyacentes de la Sociopoética dispuestas sobre la literatura de base y artículos sobre el enfoque dispuestos en la Biblioteca Virtual en Salud. RESULTADOS: Por comprender el hombre como ser político, social, con igualdad de los derechos y considerar el cuerpo, la creatividad y la espiritualidad en la construcción del conocimiento (Gauthier, 2005) para la producción y asimilación de datos, la Sociopoética permitió la construcción de relajaciones contextualizadas con los temas estudiados de manera que su alineación junto con las técnicas de producción de datos ayudan en lo descubrimiento más espontáneo y libertario por los co-investigadores en las investigaciones.

CONCLUSIÓN: La libertad creativa que ofrece la Sociopoética en la construcción de relajaciones no paraliza este paso, que permite el diálogo entre los objetivos del estudio y los pasos de los datos de producción, empezando con la relajación. Por lo tanto, se expande y aumenta la expresión de los co-investigadores en la investigación que se desarrolla.

\section{DESCRIPTORES: Relajación; Recolección de datos; Enfermería Psiquiátrica; Salud Mental}

\begin{abstract}
"Plasticity creative possible by sociopoetic: a perspective of relaxation's creation"

OBJECTIVE: Highlight the creative plasticity present in the process of creating the relaxation techniques inherent to the data production stage in sociopoetic research.

METHODS: Critical analysis of relaxations used in the academic studies production and based on qualitative research and on a sociopoetic approach. It conducted analysis based on the underlying principles of Sociopoética arranged on the basis of literature and articles on the willing approach Virtual Health Library.

RESULTS: Such an approach includes the man as a political, social and equal rights and considers the body, creativity and spirituality in the construction of knowledge (Gauthier, 2005) for production and assimilation of data, Sociopoética allowed the construction of relaxations contextualized with the themes studied so that its alignment with the data production techniques to corroborate the unveiling more spontaneous and libertarian by the co-investigators in the investigations.

CONCLUSION: The creative freedom offered by Sociopoética in the construction of relaxations not paralyzes this step, which enables dialogue between the objectives of the study and the steps of the production data, starting with the relaxation. Thus, it expands and enhances the expression of the co-researchers in the research to be developed.
\end{abstract}

\section{KEYWORDS: Relaxation; Data Collection; Psychiatric Nursing; Mental Health}

Submetido em 20-11-2016

Aceite em 20-02-2017

\footnotetext{
1 Enfermeira. Doutoranda SandWish do Programa de Pós Graduação em Ciências do Cuidado em Saúde da Escola de Enfermagem Aurora de Afonso Costa, Universidade Federal Fluminense e Escola Superior de Enfermagem do Porto, Portugal. Bolsista FAPERJ. Rio de Janeiro/RJ, Brasil, paulaisabellafonseca@gmail.com

2 Enfermeira. Mestranda do Programa de Pós Graduação em Ciências do Cuidado em Saúde da Escola de Enfermagem Aurora de Afonso Costa, Universidade Federal Fluminense, pamelagioza@hotmail.com

3 Pós Doutora em Enfermagem. Profa Titular do Departamento de Enfermagem Materno Infantil e Psiquiatria da Escola de Enfermagem Aurora de Afonso Costa, da Universidade Federal Fluminense. Niterói, RJ, Brasil, claudiamarauff@gmail.com

4 Doutor em Enfermagem. Professor Adjunto na Escola Superior de Enfermagem do Porto, ESEP, zecarlos@esenf.pt
}

Citação: Fonseca, P. I. M. N., Silveira, P. G., Tavares, C. M. M., \& Carvalho, J. C. (2017). A plasticidade criativa possibilitada pela sociopoética: a perspectiva da criação de relaxamentos. Revista Portuguesa de Enfermagem de Saúde Mental (Spe. 5), 99-106. 


\section{INTRODUÇÃO}

Idealizada por Jacques Gauthier, filósofo e educador francês, há pouco mais de 20 anos, a Sociopética foi definida em seu primeiro livro como: uma revolução epistemológica. Uma tentativa entre outras de responder as perguntas dos pesquisadores de hoje sobre o sentido sociopolítico da produção dos conhecimentos (Santos e Gauthier, 2013).

É uma abordagem do conhecimento que compreende o homem como ser político, social e com igualdade de direitos e que considera o corpo, a criatividade e a espiritualidade na construção do conhecimento (Gauthier, 2005) para produção e assimilação dos dados. Como método, a Sociopoética defende a construção coletiva do conhecimento por parte dos pesquisadores e sujeitos de pesquisa, e possui como pressuposto básico que todos possuem saberes diversos, seja intelectual, sensível, emocional, intuitivo, teórico, prático, gestual, e, sendo estes iguais em direito, transformam o ato de pesquisar num acontecimento poético (do grego poiesis $=$ criação $)($ Santos, 2005).

Estudos nessa temática tem possibilitado transcender o instituído, ousar, representando uma espécie de desbloqueio das amarras cartesianas, um disparador para o alcance do imaginário. Isso tem levado a ampliação do aprendizado e entrega, de pesquisadores à co-pesquiadores (como são chamados os participantes das pesquisas na Sociopoética), ao lúdico, ao sensível, ao espiritual potencializando assim os corpos e reflexões (Fonseca et al., 2015).

Quanto à composição teórica constituinte da abordagem sociopoética, declara-se que:

"[...]a Sociopoética [...] nasceu na encruzilhada de orientações metodológicas e teóricas que marcaram a década de 60 e 70 e continuam inspirando pesquisas inovadoras: análise institucional, pesquisa-ação e pesquisa participante, pedagogia do oprimido, grupos operativos, arte-educação, pedagogia simbólica, etc." (Gauthier, 2012, p. 75)

Embora atualmente sejam remontadas as influências sociopoéticas nas orientações teóricas acima citadas, logo num momento inicial de construção do método as linhas teóricas de base, foram: a releitura dos ensinamentos de Paulo Freire, acompanhado de outras inspirações tais como a Análise Institucional, a EsquizoAnálise, o Teatro do Oprimido de Augusto Boal e a Escuta Mitopoética de René Barbier (Gauthier, 2012; Petit, 2002).
Boal (1995) com seus exercícios pensados para preparar seus atores no teatro é um dos inspiradores do uso do relaxamento na pesquisa sociopoética, momento previsto para acontecer antes da produção de dados. Outras influencias também são citadas por Gauthier, como Freud que usava o relaxamento para enfraquecer as censuras, de modo que se permitisse passar os conteúdos pré-conscientes e inconscientes na busca da libertação pessoal; Marx com a ideia da libertação coletiva; e o Tai Chin Do (forma inicial do Tai Chi Chuan) que possibilita tornarem as energias corporais mais fluídas ao se flexibilizar os movimentos igualmente ao pensamento, favorecendo a integração do ser, ao relacionarem emoção e razão, sensações e intuição (Gauthier, 2012).

$\mathrm{O}$ autor cita no livro base para o aprendizado de conceitos primários da Sociopoética, que "existem formas de relaxamento silenciosas inspiradas em disciplinas orientais de meditação e ioga dinâmica, e outras também, [...], que esgotam os corpos e disponibilizam-nos para a aceitação simples e imediata dos conteúdos que surgem à mente." (Gauthier, 2009, p.12)

Sobre isso, é possível afirmar que existem diferentes tipos de técnicas de relaxamento, contudo alguns critérios devem ser contemplados na opção por um determinado método. Estes devem ser de fácil aprendizagem e aplicação, não requererem equipamento complexo, serem passíveis de utilizar com grupos pequenos e servirem para todas as idade (Payne, 2002).

Ademais, ressalta que o mais importante do exercício do relaxamento é fazer cessar a racionalização de tudo, promovendo por parte dos que participam da pesquisa, uma entrega a ela, permitindo que deixem surgir os conteúdos sem censura, sem ter tempo para refletir, avaliar, ou "melhorar" o que vai surgindo.

Outros autores entendem o relaxamento como usualmente utilizado na referência a momentos de alívio de tensão, em oposição, a momentos de contração muscular (Payne, 2002); um estado de consciência caracterizado por sentimentos de paz e alívio de tensão, ansiedade e medo (Borges e Ferreira, 2013).

Com este argumento, a regra imposta ao relaxamento é proporcionar ao co-participante, da melhor maneira possível, a libertação de suas amarras inconscientes de modo que este se sinta mais confortável para refletir abertamente sobre o tema que irá ser negociado para ser discutido com o grupo. Assim, ampliam-se as possibilidades de serem pensados diferentes modos de se aplicar este relaxamento. 
Ratifica-se que não se pode fugir aos princípios estabelecidos pela sociopoética, uma vez que o relaxamento aplicado está contido numa sequência lógica de etapas a serem percorridas, que tem como objetivo final a produção de dados consistentes para a pesquisa que está sendo desenvolvida.

Diante da relevância do relaxamento no preparo multidimensional dos participantes o estudo objetivou destacar a plasticidade criativa presente no processo de criação das técnicas de relaxamento inerente a etapa de produção de dados na pesquisa sociopoética.

\section{MÉTODO}

Trata-se de uma análise crítica de experiências com relaxamento realizadas em estudos sociopoéticos desenvolvidos pelos autores, que ressalta a plasticidade criativa possibilitada pela abordagem metodológica Sociopoética na criação dos relaxamentos realizados em dois estudos com níveis de aprofundamento teórico, temas e participantes distintos. São descritos os relaxamentos implementados em uma monografia de final de curso de graduação e uma tese de doutorado, ambas do curso de enfermagem e que utilizaram a Sociopoética como abordagem metodológica.

A primeira - trata-se da monografia intitulada "Estratégias de promoção à saúde mental com gestantes que convivem com doenças crônicas" - desenvolvida em setembro de 2015, por meio de três oficinas, com seis gestantes com Hipertensão Arterial Crônica e Diabetes Mellitus em atendimento no Ambulatório de Pré-Natal do Hospital Universitário Antônio Pedro (HUAP) - Niterói/RJ.

A segunda - é a tese de doutorado intitulada "O autoconhecimento e sua multidimensionalidade aplicada à equipes de transplantes" - desenvolvida com nove coordenadores avançados em transplantes, nas dependências da Universidade Federal de Ciências da Saúde de Porto Alegre (UFCSPA), e para este ensaio foram recortadas duas oficinas, desenvolvidas em abril de 2016. Ressalta-se que ambos os projetos foram aprovados no Comitê de Ética em Pesquisa do Hospital Universitário Antônio Pedro, da Universidade Federal Fluminense sob o número CAAE no: 45480915.5.0000.5243 e CAAE $n^{\circ}$ : 51110915.5.0000.5243, respectivamente. Realizou-se análise dos relaxamentos com base nos princípios constitutivos da Sociopoética dispostos em literatura de base e em artigos sobre a abordagem dispostos na Biblioteca Virtual em Saúde e na Revista Entrelugares, sem delimitação de período de publicação.
Tais princípios são: o grupo-pesquisador como dispositivo; a valorização das culturas dominadas e de resistência; a arte como ferramenta de produção; a responsabilidade ética, política, noética e espiritual do grupo-pesquisador e a valorização do corpo na produção de conhecimento (Gauthier, 2012). E é neste último princípio que está embasada a prática do relaxamento, pois o corpo inteiro é considerado como fonte de conhecimento, sendo ele composto pelas emoções, sensações, intuições, gestualidade, imaginação.

\section{RESULTADOS E DISCUSSÃO}

Os estudos sociopoéticos não podem abrir mão do relaxamento, tendo este, importância ímpar nas sessões de produção de dados (Gauthier, 2012). É desejável que o relaxamento ocorra em cada sessão, no início e no final, não sendo obrigatória a realização nestes dois momentos, mas ao menos em um deles, sendo o momento inicial o mais utilizado em estudos sociopoéticos (Elias, Tavares, Cortes, 2013; Marcondes et al., 2015; Silva et al., 2015), assim como aconteceu nos estudos explorados para esta investigação.

Neles foram utilizados relaxamentos voltados para atender os aspectos que seus respectivos pesquisadores julgaram importantes de constarem no momento de preparação dos co-participantes para a aplicação da técnica de produção de dados, pois "o objetivo do relaxamento é desencadear o potencial imaginativo do grupo, diminuindo o nível de controle consciente, para que possam expressar os saberes enterrados e imersos, os ventos raros, as larvas congeladas pela história coletiva e individual" (Gauthier et al., 1998).

Na monografia que trata das estratégias de promoção à saúde mental com gestantes com doenças crônicas, os aspectos levados em consideração para a construção do relaxamento foram: remeter ao desprendimento de problemas que pudessem trazer algum tipo de desconforto ou impedimento para que as gestantes atingissem o nível de relaxamento, tais como problemas familiares, dificuldades financeiras ou preocupações relacionadas ao desenvolvimento da gestação de risco. Além disso, os acontecimentos alegres e difíceis também foram suscitados, a fim de aflorar detalhes importantes que poderiam ser relatados após o início da oficina proposta.

Tais elementos estavam sempre aliados a existência do bebê, o qual era a principal motivação para enfrentarem as circunstâncias impostas pela gravidez e desenvolverem a gestação de uma forma saudável. 
Desta forma, seguiu-se a construção do relaxamento intitulado "Linha da Vida".

\section{Relaxamento Oficina "Linha da Vida"}

"Nesse momento agora eu vou pedir para vocês soltarem as bolsas, descruzarem os braços, as pernas, fiqucarem livres de qualquer objeto.

Fechem os olhos e respirem lentamente, puxando o ar pelo nariz e soltando pela boca, nesse momento eu começo a me desprender dos problemas lá de fora, das preocupações, das dificuldades encontradas diariamente.

E continuo a respirar lentamente, limpando minha mente e me esvaziando de tudo que não me faz bem. Agora imagine um bosque, onde existam muitas árvores e flores. Na medida em que caminhe, sinta os raios de sol ultrapassarem os galhos das árvores e chegarem até você...

Agora, coloque sua barriga de fora e sinta os raios de sol aquecerem seu corpo...

Nesse momento, passe a mão na sua barriga e sinta os movimentos do seu bebê, seu pensamento está voltado para ele e esse se torna um momento único, somente seu e dele...

Continue a caminhada pelo corredor do bosque adquirindo toda a energia transmitida pelos raios de sol e observando a paz que o balanço do vento naquelas árvores e flores te traz...

Pense em todos os momentos vividos durante essa gestação, tanto os alegres quanto os de dificuldade e lembre que em todos eles o seu companheiro mais fiel foi meu bebê, foi junto dele que percorreu todo o caminho e chegou até aqui....

Continue a passar a mão em sua barriga e a respirar lentamente....

Respire lentamente e profundamente...

E aos poucos abrindo os seus olhos."

Na sociopoética o corpo é visto como desencadeador de potências criadoras. Durante as oficinas é estimulado a sensibilidade do corpo, possibilitando uma forma de produção de conhecimento que não seja apenas racional (Silveira et al., 2008). O relaxamento que antecede a oficina prepara o co-pesquisador de uma maneira melhor para a dinâmica de grupo, uma vez que permite sua imersão no lúdico e através desta, são acessados conteúdos do inconsciente até então não explorados por outros métodos.
As dinâmicas das oficinas tornam os participantes desinibidos, comunicativos, com maior capacidade crítico-reflexivo, evoluindo sua autonomia, autocuidado e autoestima, tornando-os passíveis de mudanças para eles mesmos, para os outros e para o meio em que convivem (Said, 2001).

É possível perceber o estímulo a esta potência criadora corporal no relaxamento acima, em respeito ao princípio da corporeidade ditado pela abordagem, ao observarmos que há uma provocação à gestante quanto a prática da gestualidade sensível amplamente ancorada em seu imaginário afetivo.

Em ambos estudos utilizou-se a música associada ao relaxamento, visando um maior aprofundamento criativo e libertador em cada co-pesquisador. Sobre isso, o autor da Sociopoética não se posiciona a favor do uso da música no relaxamento, como traz no trecho "muitos facilitadores e facilitadoras gostam de apoiarse em músicas para favorecer o relaxamento, mas pessoalmente prefiro evitar tudo que poderia, de maneira aberta ou mais sutil, induzir certos dados e impedir outros." (Gauthier, 2012).

No entanto, a música é a expressão artística do homem que mais o atinge diretamente, e para a maioria das pessoas, a vivência musical, seja ouvida ou tocada, proporciona sensações relaxantes e prazerosas. Geralmente observarmos a presença da música na rotina das pessoas e o quanto ela proporciona prazer e relaxamento, aliviando tensões, emocionando, sensibilizando nossos sentidos e sentimentos mais profundos (Polo, 2010).A abordagem terapêutica da música durante o período gravídico permite as gestantes uma ligação forte com os seus bebês, e este vínculo crescerá ainda mais utilizando como recurso os afetos transmitidos através da música, melhorando assim, a qualidade da gravidez, do trabalho de parto e do nascimento do bebê, e reduzindo o nível de ansiedade da futura mãe (Castro, 2012).

Delabary (2008) revela em seu estudo que a música com seus elementos e possibilidades, pode proporcionar um espaço onde a confiança e o acolhimento complementa o clima propício para que a futura mãe pense nela própria, tenha um verdadeiro encontro consigo mesma, seja o centro das atenções naquele momento. O relaxamento através da música é visto de forma especial para gestantes, pois enquanto ocorre propicia um momento único entre mãe-filho, fazendo com que consigam relaxar, sentir os movimentos do bebê, aliviar as tensões, diminuir o estresse, manter uma respiração suave e diminuir as preocupações relacionadas a gravidez, patologia e família. 
Baseado nestas informações, portanto, optou-se pela utilização da música nos relaxamentos.

Através da experiência citada acima, em que foi possível lançar mão de um comprovado agente beneficiário aos participantes, podemos observar a capacidade oferecida pela sociopóetica de versatilidade criativa ao permitir que o relaxamento se adapte conforme a particularidade do grupo-pesquisador, visando a preparação dos co-pesquisadores para estarem mais entregues, abertos, dispostos a realização da produção de dados.

Quanto aos relaxamentos utilizados na tese de doutorado, estes foram baseados nos 4 elementos da natureza: água, ar, fogo e terra. A ideia de trabalhar com os elementos fundamentais está ancorada em Bachelard (1990A) citado por Tavares (1998) que acredita que cada um dos 4 elementos materiais pode se associar a um tipo de devaneio que comanda as crenças, o ideal, as paixões, a filosofia de vida, sendo que para cada um dos elementos há uma estética personalizada, assim como um temperamento, uma psicologia, uma poética específica, uma moral.

O autor firma a lei dos quatro elementos que classifica as diferentes imaginações materiais tal qual seja sua ligação, com o fogo, com a água, com a terra ou com o ar. E esta lei é o princípio fundamental da poética de Bachelard (1990A) citado por Tavares (1998) que não se preocupa com a qualidade mecânica fundamental de cada elemento, já que ao buscar uma linguagem na materialidade, sugere que o elemento de origem possa explicar o mundo ao prodigalizar certezas ambivalentes, sugerir confidencias secretas e mostrar imagens resplandescentes.

Ao afirmar que cada devaneio, para prosseguir, necessita encontrar sua matéria, sendo necessário que um elemento material lhe dê sua própria substância, sua própria poética específica e sua própria regra, Bachelard (1990B) citado por Tavares (1998) destaca o papel dos quatro elementos. Estes por sua vez, são fundamento do que o autor compreende por imaginação material, que é inspirado em filosofias tradicionais e cosmologias antigas. Desta maneira, os quatro elementos são estimados como hormônios da imaginação, uma vez que cada um deles acionam grupos de imagens que auxiliam na compreensão íntima do real (Bachelard 1990B citado por Tavares 1998).

Tendo por base este argumento, nestes relaxamentos buscou-se expandir a imaginação criadora e a movimentação dos corpos, mesmo que de modo sutil, com a intencionalidade de quebrar as tensões que são construídas com a exposição da imagem em grupo.
Neste caso, a parte do relaxamento voltado para o uso do corpo foi marcadamente importante visto que os participantes são da região sul do país, carregando consigo em face de sua cultura maior controle sobre a expressividade corporal, influenciados pela forte presença alemã e italiana na composição familiar.

A união dos movimentos corporais ao imaginário de modo a colocar o pensamento em fluxo no contexto atual, exige do corpo movimentos em sintonia com afetos e ideias, o que coloca em relação certas forças de invenção do mundo e de si mesmo. Indubitavelmente, isto implica romper com um tipo de alienação entendida como inatividade física, mas também com outras formas de alienação: diminuição da capacidade de pensar e agir por conta própria, crescente sentimento de solidão e isolamento, inércia intelectual, embotamento da criatividade e da expressão, indiferença e falta de cuidado com os outros e o mundo, perturbação mental, falta de sensibilidade (Amaral e Gentini, 2012).

Em prosseguimento, seguem abaixo os relaxamentos:

\section{Relaxamento oficina 1 - elemento terra}

"Este momento é para relaxarmos. Neste curso vamos trabalhar com as emoções, com o autoconhecimento, então assim é um momento para a gente tentar se esforçar em deixar os plantões ou a rotina. É o momento de vocês fecharem os olhos. Vou pedir para vocês respirarem fundo, inspirando pelo nariz e soltando pela boca. Vou pedir para vocês fazerem isso de maneira tranquila. Que todo o ar saia, que toda a preocupação saia. Todo ar que sai, saia com aquilo que eu não quero que esteja aqui neste momento.

$\mathrm{Eu}$ inspiro tranquilamente e expiro devagar. Eu vou começar a deixar os meus ombros soltos, mexendo-os para trás, sentindo-os. Sentindo o peso dos meus ombros. Inspiro e expiro. Eu vou deixando meus braços pesados, soltando minhas mãos, deixando meus dedos livres.

Inspiro e expiro.

Vou sentindo minha musculatura abdominal. Vou relaxando. Estou relaxando e ficando mais pesado. Começo a pensar num sol nascendo num campo verde. Eu inspiro uma brisa suave tocar meus poros, o inspiro até chegarem aos meus alvéolos e esse ar me limpa... me revigora.

Meu corpo está relaxado e eu caminho tranquilamente sobre este campo. Há flores, há muita calma neste campo. 
Eu sinto meus pés relaxarem, sinto meus pés caminhando vagarosamente, sem pressa. Meu corpo está relaxado.

Eu estico meus braços para frente, e solto meus braços lentamente.

Eu inspiro fundo e expiro fundo, e faremos três inspirações e expirações para finalizarmos. Uma [pausa], duas [pausa], três [pausa].

Bem vindos de volta! Podem se sentar."

\section{Relaxamento oficina 2- elemento ar}

"Feche os olhos e respire profundamente por 3 vezes. Você vai preparar o seu corpo para uma viagem pela imaginação. Neste momento, se aproxima de você uma grande bolha transparente. Seu corpo é sugado pela bolha.

Respire.

A bolha começa a se movimentar com você.

Preste atenção aos movimentos da bolha. A bolha ti leva a vários lugares das vivências emocionais.

Comece a se movimentar pelos lugares das vivências emocionais. Ande pelos lugares das vivências emocionais. Procure percorrer inclusive os lugares que você não conhece.

Como você está se sentindo nos lugares das vivências emocionais? Como são estes lugares? De repente, você tenta pegar na bolha, não consegue.

A bolha fura e você cai num lugar escuro. Você olha ao redor e percebe que está numa sala rodeada de imagens de vivências emocionais.

Respire fundo e abra os olhos."

Destaca-se que a respiração é o item que dá início aos relaxamentos do segundo estudo. A literatura base da Sociopoética destaca que a técnica mais simples de se realizar o relaxamento é relacionada à percepção consciente da respiração, do sopro, de cada parte do corpo (Gauthier, 2012). Desta maneira, a respiração profunda, calma, sentida pelo co-pesquisador o aproxima do estado de relaxamento, como é possível observar sendo realizado no "Relaxamento do elemento terra", em que se fragmenta o corpo respiratório por meio de seus acessos e caminhos: boca, pulmões, diafragma.

Exercícios como estes são conhecidos como exercícios de respiração mindfulness, nos quais os participantes são convidados a dirigir a sua atenção para a respiração, sendo guiados para diferentes partes do corpo onde poderiam sentir a respiração (nariz, pescoço, peito, abdómen, diafragma, região abdominal).
Estudo afirma que focar a atenção nas diferentes partes do corpo através da respiração traz resultados seja em nível físico, seja em nível mental, por exemplo, ao focar a atenção no diafragma ou na parte abdominal, abranda-se a respiração, e acalma-se a mente, reduzindo a tensão ou ansiedade (Lima, Oliveira e Godinho, 2011). A possibilidade de humanização está ligada à aplicação de tecnologias simples que muitas vezes não são valorizadas em detrimento das mais sofisticadas (Carraro, 2000) e a respiração controlada e sentida é uma dessas tecnologias que podem ser usadas em nosso favor.

Outro elemento que esteve presente nos relaxamentos do segundo estudo foi a música relaxante. Esta foi utilizada como pano de fundo para possibilitar uma imersão mais completa dos co-pesquisadores no que estava proposto nas atividades.

A música pode ser considerada uma tecnologia simples se considerarmos que nossa cultura é muito musical (Carraro, 2000). Podemos também apontar a música como uma tecnologia inovadora de cuidado se for organizada como uma atividade ao mesmo tempo sistemática e criativa, pois facilita a expressão de emoções, a comunicação interpessoal e a possibilidade de se focalizar aspectos saudáveis do outro (Bergold e Alvim, 2009).

Estudo que faz um apanhado geral sobre a aplicação de técnicas criativas na abordagem Sociopoética, ressalta que dinâmicas de relaxamento/sensibilização foram utilizadas em todos os artigos levantados. Ora com músicas propícias para relaxamento ora com massagem e alongamento, mas todas com o intuito de desbloquear as emoções dos sujeitos e possibilitar o encontro com seus imaginários (Fonseca et al., 2015). Como é possível perceber o relaxamento marca o encontro ritualístico do grupo e sua institucionalização como grupo-pesquisador, favorecendo o encontro entre os copesquisadores, a confiança mútua, a expressão espontânea, o encontro e superação dos medos, a formação de um coletivo acolhedor que, por outro lado, não deixe de mobilizar um forte espírito crítico e autocrítico. Acolhimento e espírito crítico crescem juntos (Gauthier, 2012).

Diferente do primeiro estudo, os relaxamentos produzidos no segundo estudo não guardaram relação com a ocupação dos co-pesquisadores, pois não envolveram o tema doação de órgãos ou transplantes. Ainda sim, os relaxamentos cumpriram o objetivo do pesquisador de libertar os conteúdos racionais dos co-participantes da melhor maneira possível, pois estimularam não 
somente o movimento corpóreo, mas também o imaginário, o fantasioso e o lúdico, conforme se prevê como resultado desta etapa que antecede a produção de dados.

Sendo assim, o relaxamento representa um momento - até certo ponto, já que tem princípios a serem seguidos - um tanto desprendido das amarras das regras metodológicas, trazendo consigo uma plasticidade criativa que encontra limites somente no potencial inovador de quem o cria.

\section{CONSIDERAÇÕES FINAIS}

A liberdade criativa oferecida pela Sociopoética na construção dos relaxamentos não engessa esta etapa, o que possibilita o diálogo e alinhamento entre os objetivos do estudo e os passos da produção de dados, a começar pelo relaxamento. Deste modo, amplia-se e se potencializa a expressão dos co-pesquisadores na pesquisa a ser desenvolvida.

Nos relaxamentos trazidos neste estudo foi possível observar que há possibilidade de se construir esta atividade, consonante com o tema a ser desenvolvido na pesquisa, criando um ambiente, em alguns casos, mais confortável para os co-pesquisadores, e também há a possibilidade de se desenvolver relaxamentos que não necessariamente estejam envolvidos com o tema a ser negociado. Nestes últimos, os objetivos traçados para serem alcançados são diversos, como os utilizados na tese de doutorado que buscaram, trabalhar com questões como a timidez do grupo, trabalhar a construção de um ambiente mais liberto das amarras institucionais e com a quebra de alguns comportamentos culturais.

Diante disto, sugere-se a realização de mais estudos que avaliem os tipos de relaxamentos aplicados em pesquisas sociopoéticas de modo que verifiquem se há ou não, alinhamento destes com as técnicas de produção de dados elencadas pelos pesquisadores, podendo ainda observar se isto causa impacto na participação dos co-pesquisadores e consequentemente na qualidade final dos dados produzidos.

\section{REFERÊNCIAS}

Amaral, A., Gentini, A. (2012). Emergências do corpo nos processos de educação ambiental: inventos e outros modos de existência. In: Adad, S., Júnior, F. (Orgs.) Corpografia: Multiplicidades em fusão. Fortaleza. Edições UFC.
Bachelard, G. (1990A). A terra e o devaneio do repouso. In: TAVARES, C.M.M. A imaginação criadora como perspectiva do cuidar na enfermagem psiquiátrica.1998. 195f. Tese doutorado. Escola de Enfermagem Anna Nery, Universidade Federal do Rio de Janeiro, Rio de Janeiro.

Bachelard, G. (1990B). O ar e os sonhos. In: TAVARES, C.M.M. A imaginação criadora como perspectiva do cuidar na enfermagem psiquiátrica.1998. 195f. Tese doutorado. Escola de Enfermagem Anna Nery, Universidade Federal do Rio de Janeiro, Rio de Janeiro.

Bergold, A. (2009). Música terapêutica como tecnologia aplicada ao cuidado. Esc Anna Nery Rev Enferm. 13 (3): 537-42. Disponível em: http://www.scielo.br/ pdf/ean/v13n3/v13n3a12

Borges, E., \& Ferreira, T. (2013). Relaxamento: Estratégia de intervenção no stress. Revista Portuguesa de Enfermagem de Saúde Mental (10), 37-42. Disponível em: <http://www.scielo.mec.pt/scielo.php?script=sci_ arttext\&pid=S1647-21602013000200006\&lng=pt.

Boal, A. (1995). 200 exercícios e jogos para o ator e não-ator com vontade de dizer algo através do teatro. Rio de Janeiro: Civilização Brasileira.

Carraro, T. (2000). Tecnologia e humanização: da sua união às possibilidades de prevenção de infecções. Texto Contexto Enfer, 9(1):42-61.

Castro, C. (2012). Comparação da eficácia entre música sugerida emúsica preferida na indução de relaxamento na gravidez. 98 f. Dissertação (Mestrado em Musicoterapia) - Instituto de Psicologia e Ciências, Educação da Universidade Lusíada de Lisboa, Lisboa. Disponível em: http://repositorio.ulusiada.pt/handle/11067/534

Elias, A., Tavares, C., \& Cortez, E. (2013). Impacto do estigma da loucura sobre a atenção de enfermagem ao paciente psiquiátrico em situação de emergência. Ciência, cuidado e saúde. 12(4). Disponível em: $<$ http://periodicos.uem.br/ojs/index.php/CiencCuidSaude/article/view/22553 >. Acesso em: 27 Out. 2016.

Fonseca, P., Elias, A., Oliveira, F., \& Tavares, C. (2015). Aplicaçãode técnicas criativas napesquisaSociopoética: poetizando os achados pela análise de conteúdo. RevEntrelugares. 7 (1). Disponível em: <https://drive.google. com/file/d/0B3jPkFT2UePjTXdTbDM0YmxoQ00/ view $>$. Acesso em: 26 Out. 2016. 
Gauthier, J., Santos, I., Souza, L., \& Figueiredo, N. (1998). A sociopóetica: uma filosofia diferente e prazerosa. In: Gauthier, J., Cabral, I.; Santos, I., Tavares, C. (Orgs.). Pesquisa em enfermagem: novas metodologias aplicadas. Rio de Janeiro: Guanabara Koogan.

Gauthier, J. (2005). Princípios filosóficos da sociopoética. In: Santos, et. al. Prática de pesquisa nas ciências humanas e sociais: abordagem sociopoética. (Série atualizações em enfermagem, V. 3), São Paulo: Atheneu.

Gauthier, J. (2009). Sociopoética - O livro do iniciante e do orientador. Edição Eletrônica.

Gauthier, J. (2012). O oco do vento. Metodologia da pesquisa sociopoética e estudos transculturais. Curitiba, PR: CRV.

Lima, M., Oliveira, A., \& Godinho, P. (2011). Promover o bem-estar de idosos institucionalizados: Um estudo exploratório com treino em mindfulness. Revista Portuguesa de Pedagogia. Disponível em: $<$ http://impactumjournals.uc.pt/index.php/rppedagogia/article/ view/1299>. Acesso em: 25 de Out. 2016.

Marcondes, F., Tavares, C., Fonseca, P., Silveira, P., Silva, L., \& Manhães, L. (2015). Reflexões sobre o processo de educação permanente da equipe do Programa de hipertensão e diabetes no município de Niterói: estudo Sociopoético, In: I Encontro Internacional de Inovação no Ensino na Saúde e Enfermagem I Simpósio Internacional de Inovação no Ensino de Saúde Mental, Saúde Coletiva e Saúde da Mulher. Niterói, Rio de Janeiro, Brasil.

Payne, R. (2002). Técnicas de relaxamento. Loures: Lusociência.

Petit, S. (2002). Sociopoética: potencializando a dimensão poiética da pesquisa. In: Matos, Kelma S. Lopes, Vasconcelos, José (Orgs.). Registros de pesquisas na educação. Fortaleza: UFC. Diálogos Intempestivos, 6 .
Polo, C. (2010). Intervenções Lúdico-musicais frente ao estresse de crianças acolhidas vítimas de violência doméstica. 135 f. Dissertação (mestrado em Psicologia da Saúde) -Faculdade de Saúde, Universidade Metodista de São Paulo, São Bernardo do Campo, Disponível em: <http://tede.metodista.br/jspui/bitstream/ tede/1451/1/Christianne\%20Kamimura.pdf> Acesso em: 29 Out. 2016.

Said, F. (2001). Dinâmicas pedagógicas na perspectiva da educação em saúde. Curitiba: [s.n.],

Santos, I. (2005). Sociopoética. Uma Ponte para o Cuidar / Pesquisar em Enfermagem. Index de Enfermería [Index Enferm] (edição digital), Espanha, 50. Disponível em: <http://www.index-f.com/indexenfermeria/50revista/p5233.php >. Acesso em: 27 Out. 2016.

Santos, I.; Gauthier, J. (2013). Sociopoética: para uma perspectiva estética do pesquisar/cuidar/educar em enfermagem. Revista Eletrônica de Enfermagem, Goiânia, 15(1) 12-4, Disponível em: <https://revistas. ufg.br/fen/article/view/15136>. Acesso em: 13 maio 2017. doi:https://doi.org/10.5216/ree.v15i1.15136.

Silva, T., Tavares, C., Fonseca, P., Paiva. L., Marcondes, F., \& Souza, R. (2015). Trabalho no processo de doação para transplante: o que dizem os componentes das equipes. In: I Encontro Internacional de Inovação no Ensino na Saúde e Enfermagem I Simpósio Internacional de Inovação no Ensino de Saúde Mental, Saúde Coletiva e Saúde da Mulher. Niterói, Rio de Janeiro, Brasil.

Silveira, L., Almeida, A., Macedo, S., Alencar, M., \& Araújo, M. (2008). A sociopoética como dispositivo para produção de conhecimento. Comunicação Saúde Educação, 12(27). Disponível em: <http://www.scielo. br/pdf/icse/v12n27/a16v1227.pdf > Acesso em 28 Out. 2016. 